\title{
Modification of Polyethersulfone Membranes to Remove Produced Water Dirt into Clean Water
}

\author{
Malikhatul Hidayah ${ }^{1}$, Tutuk Djoko Kusworo ${ }^{2}$ \\ ${ }^{1}$ Department of Chemistry, Universitas Islam Negeri Walisongo, Indonesia. 50185 \\ ${ }^{2}$ Department of Chemical Engineering, Universitas Diponegoro, Indonesia. 50275 \\ \{malikha@walisongo.ac.id ${ }^{1}$,tdkusworo@che.undip.ac.id²\}
}

\begin{abstract}
Produced water contains organic and inorganic contaminants that can pollute the environment The high demand for oil and gas causes continuous exploration. In the process of mining oil and gas large quantities of produced water are produced. Produced water is a by-product of oil and gas processing. Proper processing is needed to make the produced water well utilized. Membrane is an alternative water treatment technology with the principle of filtration. However, in the use of membranes it still has many shortcomings, among others, still the formation of fouling and still not meeting the quality standards of clean water. This is what underlies the research to study the use of materials that can overcome membrane fouling and an efficient system that can make produced water into clean water. In this study, polyether sulfone membrane (PES) with dry / wet phase inversion method and also polyether sulfon nanohybrid (PES) -nano $\mathrm{ZnO}$ membrane were made with PES $18 \mathrm{wt} \%$ and $\mathrm{ZnO} 0.5 ; 1 ; 1.5 \% \mathrm{wt}$. This study also examined the effect of UV light on the membrane for 1.5 .10 minutes and the effect of heating at $180 \mathrm{oC}$ for 10 seconds. A double stage system is used to improve membrane performance. SEM analysis is used to show that PES membranes have larger pores due to UV irradiation and show a denser membrane pores after heating. Contact angle analysis was also conducted to show that $\mathrm{ZnO}$ nanoparticles can improve the hydrophilic properties of membranes. To find out the results of membrane performance, TDS, Cl-, S2- and turbidity analyzes were carried out. The four analyzes showed results that significantly declined. With this system, inorganic and organic particles have been held more at the membrane surface. However, in this study, it is still necessary to examine the proper temperature that can improve membrane performance and make comparisons with the performance of membranes that use other nano-particles so that water quality standards can be met.
\end{abstract}

Keywords: Polyethersulfone, ZnO, SEM, UV, TDS, Produced water.

\section{Introduction}

Produced water is a by-product of oil and gas processing. This water is different from water usually because it contains hazardous chemicals and other elements contained in the oil and gas (Nadia, 2015). Produced water will increase with the age of oil or gas land, but good processing and opening up of new oil or gas land will reduce the amount of produced 
water (Ahmadun et al., 2009). Proper processing is needed to make the produced water well utilized. In produced water processing, ultafiltration and nanofiltration membranes can be used because they have a pore size of 0.001 microns so that the combination can improve performance for making clean water and can filter waste water with high organic content (Alzahrani et al., 2018). However, the use of membranes still has many disadvantages, among others, still forming fouling. This is what underlies the research to examine the use of materials that can overcome fouling on the membrane.

In this study obtained the results of microfiltration membrane is a membrane that provides the best results seen based on flux value and water quality. Whereas the reverse osmosis membrane is more effective for further water treatment after proper pre-treatment. Still the occurrence of fouling is a deficiency in this study. Therefore it is necessary to develop a membrane that does not cause fouling.

(Cathie Lee et al.,2012) investigated polysulfone (Psf) membranes mixed with $\mathrm{ZnO}$ nanoparticles to reduce fouling from oleic acid. Leo, et al. Stated that the addition of nano $\mathrm{ZnO}$ will greatly reduce the hydrophobicity of Psf with a quantity of $2 \mathrm{wt} \%$ and also increase the water permeability of Psf. In addition, the addition of $\mathrm{ZnO}$ also increases the thermal stability of the Psf membrane. However, the size of the pores on the membrane is slightly enlarged because of the agglomeration of these nanoparticles. But when nano $\mathrm{ZnO}$ is combined with PES, therefore in this study will be developed the use of nano $\mathrm{ZnO}$ is expected to reduce agglomeration and can be mixed between organic and inorganic in the manufacture of mixed matrix membrane (MMM). Then the use of ultraviolet will be developed, where the use of ultraviolet will help to eliminate interfaces or defects that occur between polymeric and inorganic membranes. Furthermore, this research will also develop a combination of polyether sulfone (PES) ultrafiltration membrane as a produced water initial treatment and then proceed with polyethersulfone (PES) -nano $\mathrm{ZnO}$ nanofiltration membrane.

The purpose of using the polyether sulfone ultrafiltration membrane (PES) is as an initial process to remove impurities in the produced water and then the process will be refined into clean water on the $\mathrm{ZnO}$-polyether sulfone (PES) nanofiltration membrane. Specifically the purpose of this study is to determine the nano $\mathrm{ZnO}$ concentration variable that most influences the performance of the hybrid polyethersulfone (PES) -nano $\mathrm{ZnO}$ membrane, determines the variable UV radiation and the thermal variable annealing for processing produced water into clean water.

\subsection{Membrane}

Membrane technology has developed rapidly, both on a laboratory and commercial scale. Membranes are defined as a porous, thin film, semi-permeable media that functions to separate molecular-size particles (species) in a system of solutions. With many advantages, the use of membranes also has limitations, namely the occurrence of fouling or polarization of concentration in the membrane so that the membrane needs to be washed regularly, fouling is a serious problem in membrane separation systems, especially in membrane microfiltration and ultrafiltration.

\subsection{Polyeter Sulfone Membrane (PES)}

Polyether sulfone is a polymer with a series of aromatic and sulfur ether groups. The molecular formula of polyester sulfone can be seen in Figure 2.4 


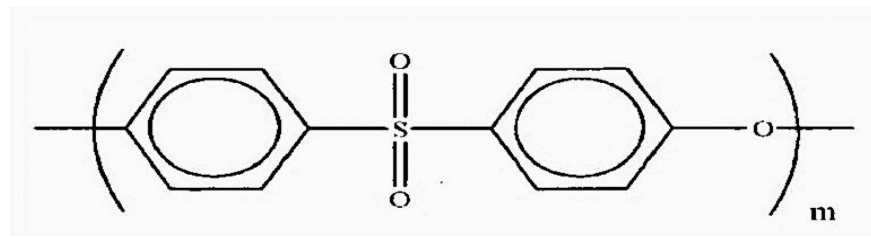

Figure 2.4 Formula of Sulfone Polyether molecules (Kusworo, 2008)

One of the many filtration membranes that is currently developed is polyethylene sulfone (PES) membranes. Polymer polyethersulfone (PES) is a polymer that is widely used in membrane microfiltration and ultrafiltration processes because it has chemical resistance and stability as well as good mechanical properties. However, PES polymers are hydrophobic so that membrane flux will decrease during operation because of the formation of fouling on the membrane (Baker, 2010).

\subsection{Irradiation of Ultra Violet Light}

Ultra violet light (UV) is light with a wavelength shorter than visible light, but longer than X-rays. UV light is an electromagnetic wave with a wavelength between $400 \mathrm{~nm}$ and $10 \mathrm{~nm}$, with energy from $3 \mathrm{eV}$ to $124 \mathrm{eV}$. UV light is more energetic than visible light because it has a short wavelength that allows it to more easily penetrate through obstacles. In addition, it is also used to kill pathogenic bacteria in drinking water. UV rays on the membrane are used to make the membrane vulnerable to reaction, so the polymer chain must contain double bonds, hydroxyl groups, or benzene rings (Nunes and Peinemann, 2001).

\subsection{Annealing temperature}

Temperature annealing or heating is related to the movement of polymer molecular chains. The increase in heating will increase the performance of the membrane because the regulation of membrane molecules becomes more stable (Kim et al., 2001).

\subsection{Membrane Characterization}

Important criteria in determining membrane performance can be seen from the parameters of flux (permeability), rejection (selectivity), and morphological structure of the membrane (Mulder, 1996). These criteria are explained further below.

\section{Flux and rejection}

Optimal conditions in membrane performance are generally expressed by the magnitude of membrane permeability and selectivity (Wenten et al., 2002). Permeability or flux flowing through a membrane is defined by the amount of permeate volume passing through the membrane per unit surface area per unit time.

\section{Scanning Electron Microscopy (SEM)}

Electron microscopy (EM) is an electron microscope based technique that is often used to see the surface of a solid. Two basic EM techniques can be divided into 2 groups, scanning electron microscopy (SEM) and transmission electron microscopy (TEM). Of these two techniques, SEM is a simple and very convenient method for characterizing and observing the pore structure of a membrane (surface and cross section). 


\subsection{N-Methyl 2 Pyrolidine (NMP)}

The solvent used in this study was NMP. NMP is an organic compound consisting of 5 lactam groups. Liquid NMP is colorless or clear and can turn yellow when it has impurity. Misibel to water and some other organic solvents. NMP is aprotic dipolar like dimethylformamide. NMP is produced industrially using the esterification process (Harreus, 2011)

\subsection{Produced water}

Increased oil production is offset by the increasing amount of waste generated from exploration. buni oil, petroleum exploration waste is called produced water (produced water) which contains organic and inorganic materials that have the potential to be B3 (Toxic and Hazardous Materials) that affect the environment and human health. Produced water treatment can be done by disposing it to the nearest environmental water body as wastewater by meeting water quality standards (Kusworo,2014). Waste water that can be injected in the form of fluid carried upwards from strata containing hydrocarbons during oil and gas and geothermal extraction activities, and can be mixed with wastewater originating from processing plants which are an integral part of the production process, unless the waste is declared as hazardous and toxic or radioactive waste.

\subsection{Zinc Oxide (ZnO)}

Zinc oxide $(\mathrm{ZnO})$ is an inorganic compound that is in powder form and is white to yellowish white. $\mathrm{ZnO}$ is used usually as an additive in products and materials such as plastics, ceramics, glass, cement, rubber (for example for rubber tires), lubricants, and others(Mushtaq et al.,2016). Zinc oxide is a unique material or material that has semiconductor and piezoelectric properties.

\section{Material and Methods}

Materials, materials used in this study include: polyether sulfone (PES) from Merck, nmethyl-2-pyrrolidone (NMP) from Merck, nano ZnO from Center Indonesia, PVP, clean water and manufactured water, while Tools Used this research is turbidimeters, magnetic stirrers, glass plates, coagulation tanks, casting knives, masking tape, ovens, UV irradiation equipment, SEM equipment, titration equipment, and dead end filtration equipment.

The research method was carried out in 3 stages, namely the stage of making polyethersulfone (PES) membrane with nano $\mathrm{ZnO}$, membrane characterization stage and membrane application stage for processing produced water into clean water. At the stage of making ultrafiltration polyethersulfone (PES) -nano $\mathrm{ZnO}$ membrane begins by making a print solution consisting of polyethersulfone (PES) with a composition of $18 \mathrm{wt} \%$ in total solids mixed with nano $\mathrm{ZnO}$ with a composition of $0.5 \mathrm{wt} \%, 1 \mathrm{wt} \%$ and $1,5 \mathrm{wt} \%$, with nmethyl-2-pyrrolidone (NMP) solvent $80 \mathrm{wt} \%$ of total solids. Membrane printing using dry wet phase inversion method. This method is done by printing a membrane on a glass plate using a casting knife.

To examine the effect of UV light exposure, before dipping it into the coagulation bath, the membrane mold on the glass plate is illuminated with UV light for 1 minute, 5 minutes, and 10 minutes, then the glass plate is dipped into the coagulation bath. The printed membrane is then left for 1 day in cold water. The membrane is then dried at atmospheric temperature for 1 day. Then thermal annealing was carried out at $180 \mathrm{oC}$ for 10 seconds. After that, membrane characterization was followed by determining the flux and membrane 
rejection, Determining the morphological structure of the membrane and the Application of Polyether Sulfone Membrane for Processing Produced water. To analyze turbidity produced water is carried out with a turbidimeter by analyzing the value of NTU produced water before and after passing through the membrane. TDS measurements were carried out using a TDS meter while Cl- and S2-ion analysis was carried out with argentometry and iodometry.

\section{Results and Discussion}

\subsection{Modification of Membrane Making}

\section{Scanning Electron Microscopy (SEM) Analysis}

The membrane was analyzed by SEM to determine how the morphological structure of the membrane. The results of the Scanning Electron Microscopy analysis using an electron microscope (Mulder, 1996). There are several membranes tested in this analysis, including PES $18 \mathrm{wt} \%$ membrane, PES $18 \mathrm{wt} \% 0.5 \mathrm{wt} \% \mathrm{ZnO}$, and PES $18 \mathrm{wt} \% 0.5 \% \mathrm{ZnO}$ with 10 minutes $\mathrm{UV}$ and thermal annealing at $180 \mathrm{oC}$. These three membranes are membranes before filtration. While the membrane after filtration used PES $18 \mathrm{wt} \% 0.5 \% \mathrm{ZnO}$ membrane with 10 minutes $\mathrm{UV}$ and thermal annealing at $180 \mathrm{oC}$.
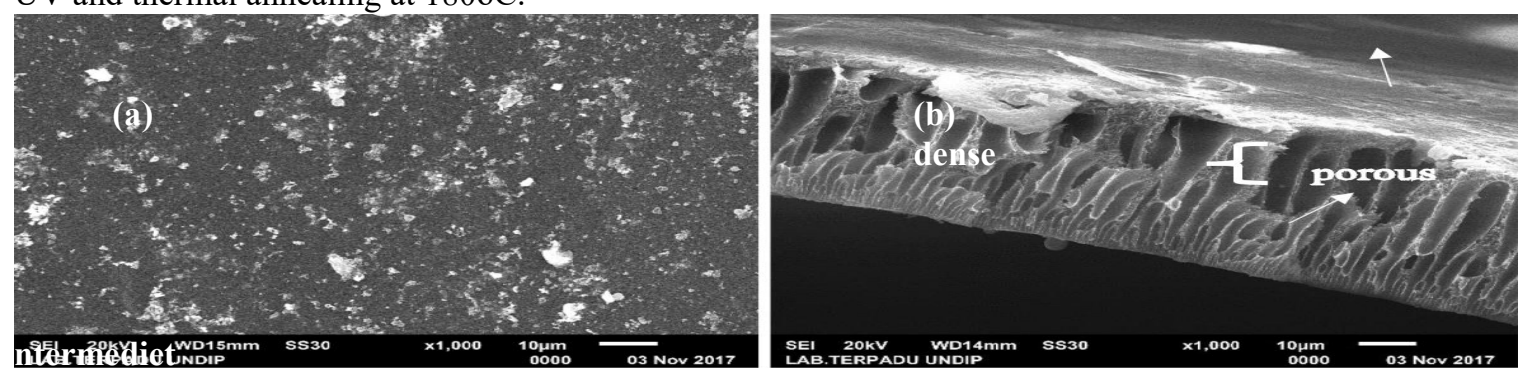

Figure 3.1 SEM analysis on surface and transverse PES membrane $18 \mathrm{wt} \% 0.5 \mathrm{wt} \%$ $\mathrm{ZnO}$ with UV 10 minutes thermal annealing at $180 \mathrm{oC}$ after fitration

Figure 3.1 clearly visible particles held up in cross section analysis, the same asymmetric membrane is formed, Fouling formed on the surface of the membrane is the accumulation of particles held during the filtration process. Fouling that is formed causes the performance of the membrane to decrease over time. However, fouling is also an indicator that the membrane is functioning properly, because if the membrane functions properly, then surely on the surface of the membrane unwanted particles will be held back. But with the influence of $\mathrm{ZnO}$ on the membrane, it can reduce the formation of fouling. It can be seen in Figure 3.1 that not too much fouling is formed.

\subsection{Effect of Ultraviolet (UV) Radiation on Membrane Performance}

Separation using membranes can add modification to the membrane, one of which is modification with ultraviolet (UV) irradiation. UV irradiation is carried out before the membrane is inserted into the coagulation bath. To see the effect of ultraviolet (UV) on membrane performance, several variables were made. UV irradiation was carried out in 1, 5, and 10 minutes for each variable PES $\mathrm{ZnO} 0.5 \mathrm{wt} \%$, PES $\mathrm{ZnO} 1 \mathrm{wt} \%$, and $1.5 \mathrm{wt} \%$. Membrane performance after modification is seen from the value of the flux and its rejection value. 


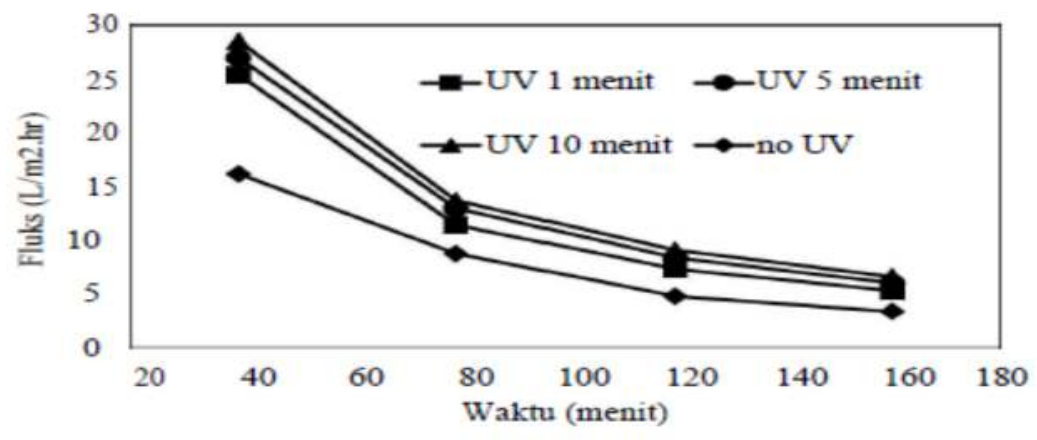

Figure 3.2 Effect of UV Irradiation on Membrane Fluxes

Figure 3.2 Effect of UV irradiation on fluk values Indicates membrane flux decreases along with the length of filtration time. The highest flux value is at PES nano- $\mathrm{ZnO} 0.5 \%$ wt with a duration of 10 minutes irradiation. In the initial state, the membrane flux value is $28.56 \mathrm{Lh}-1 \mathrm{~m}$ 2 and then decreases to $6.70 \mathrm{Lh}-1 \mathrm{~m}-2$. Meanwhile, the lowest flux value is on PES-ZnO $0.5 \%$ wt Membrane without UV irradiation. This phenomenon is caused by the cutting of polymer chains (chainscission) and crosslinking (crosslinking) (Susanto et al., 2006) when irradiating with UV light.

\section{Effect of UV Radiation on Membrane Rejection}

Membrane performance can also be seen from the percent of the reaction. Therefore it is necessary to do a rejection test. Filtration or permeate results are taken every 40th, 80th, 140th and 160th minute, then analyzed the TDS results, S2-levels, Cl- levels and turbidity or turbidity so that each percentage of the sample is obtained. TDS or Total Dissolved Solids is the total dissolved solid in a solution or water, the lower the TDS value, the better the quality of the water. TDS measurements were carried out with TDS meters while the S2- and Cl- ion analysis was applied to the permeate using titration.

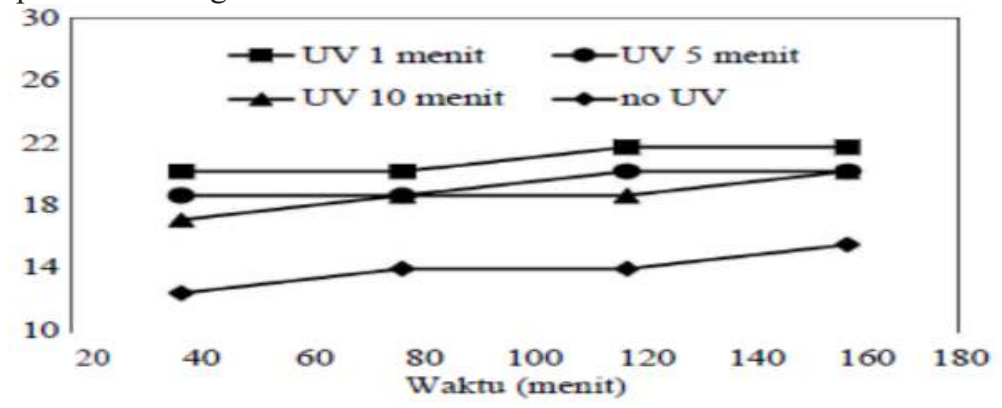

Figure 3.3 Effect of UV Radiation on TDS Rejection 


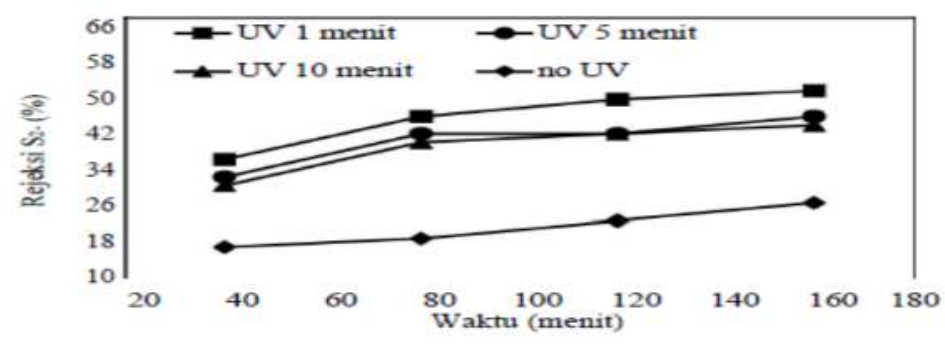

Figure 3.4 Effect of UV Irradiation on S2 Rejection

Figure 3.3 shows the effect of UV irradiation on percent TDS rejection. Based on the image, it can be seen that the longer the time of filtration or filtration, the value of membrane rejection increases. However, the longer the UV percent radiation rejection decreases. The S2 ion rejection percentage is shown in Figure 3.4. It can be seen from the figure that the phenomenon of TDS rejection is also experienced by the S2 rejection - that is, the longer the screening rejection value increases but the longer the UV irradiation is carried out, the percent rejection decreases

\subsection{Effect of ZnO Concentration on Membrane Performance}

\section{Effect of $\mathrm{ZnO}$ Concentration on Membrane Fluxes}

In knowing the effect of adding $\mathrm{ZnO}$, it is necessary to see how the membrane's performance is. One of the membrane performance can be seen from the membrane flux value. The flux value of a membrane can be calculated by comparing the membrane permeate flow rate per unit area per unit time per unit pressure.

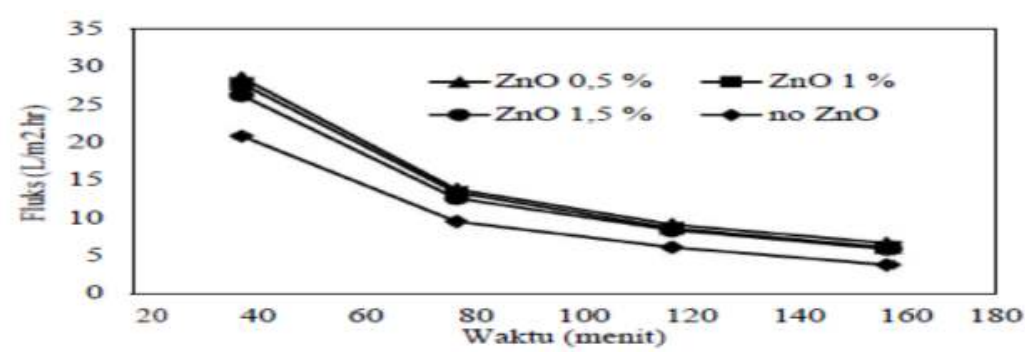

Figure 3.5 Effect of $\mathrm{ZnO}$ Concentration on Flux

From Figure 3.5 it can be seen that with increasing time, the flux value of the membrane will tend to decrease. This can occur because the longer the filtration time, the pressure from the filtration process will also increase. The increase in pressure indicates fouling that occurs on the surface of the membrane. The fouling that occurs also shows that the membrane works well because it is able to filter particulates, so it will accumulate on the surface of the membrane. The longer the use of the membrane, the dirt on the surface of the membrane will also increase, which can cause the membrane pores to be closed. This is what makes the pressure rise, the work of the membrane gets heavier and results in a decrease in the volume of the permeate produced. The decrease in volume produced causes a decrease in the value of the flux as well, 
because the value of the flux is directly proportional to the volume of the permeate produced at a certain time. Aside from the decrease in flux, it can also be seen from Figure 3.5 that there is a difference in the flux value of each concentration of $\mathrm{ZnO}$, where the flux value added by $\mathrm{ZnO}$ is higher than without $\mathrm{ZnO}$. This is because $\mathrm{ZnO}$ can increase the hydrophilic membrane. However, the addition of $\mathrm{ZnO}$ which is excessive or not in accordance with the optimum is $0.5 \mathrm{wt} \%$ causing the flux value to be lower than the optimum concentration (Stefan, 2012). Because too much $\mathrm{ZnO}$ will make $\mathrm{ZnO}$ aggregation, where $\mathrm{ZnO}$ will accumulate in one point or not spread as a whole. So, in filtration it will not be optimal. Then it is very important if in addition $\mathrm{ZnO}$ must pay attention to its optimum conditions. In this study the optimum condition of $\mathrm{ZnO}$ was $0.5 \mathrm{wt} \%$.

\section{Effect of $\mathrm{ZnO}$ Concentration on Membrane Rejection}

Membrane performance can also be seen in membrane rejection values. Membrane rejection values can be measured when performing a filtration process, together with membrane flux measurements. In calculating membrane rejection that needs to be seen is the concentration of permeate after filtration and the concentration of produced water before filtration. Rejection measurements are based on the rejection of each membrane against TDS, turbidity, S2-ion and Cl- ion

\section{Conclusion}

In this study the polyethersulfone (PES) -nano $\mathrm{ZnO}$ membrane was made to process produced water into clean water by phase inversion dry-wet method.

1. The effect of $\mathrm{ZnO}$ nano concentration on membrane performance can increase flux and rejection because $\mathrm{ZnO}$ has properties that can improve the hydrophilic properties of membranes.

2. Along with the duration of UV irradiation the membrane flux value increases but at the rejection value it decreases and makes the membrane pore more dense. However, along with the duration of the filtration process, the flux value will decrease while the percent value of the rejection will increase.

3. 3. Heating on the membrane causes the membrane flux value to decrease. This can happen because the membrane heated at $180 \mathrm{oC}$ is closer to the glass transition temperature of the PES polymer $(\mathrm{Tg}=220 \mathrm{oC})$.

The warm-up treatment causes the rearrangement of membrane molecules so that the resulting membrane will be denser. Particulates will be well-held on the surface of the membrane, because the porosity is getting denser. This is what causes the rejection produced by the thermal membrane annealing higher than without thermal annealing.

\section{References}

[1] Ahmadun, F.R., Pendashteh, A., Abdullah, L.C., Biak, D.R.A., Madaeni, S.S., Abidin, Z.Z. 2009. Review of Technologies for Oil and Gas Produced water Treatment, Journal of Hazardous Materials, vol. 170, pp. 530-551. 
[2] Alzahrani, S., \& Wahab, A. 2014. Journal of Water Process Engineering Challenges \& trends in membrane technology implementation for produced water treatment: A review. Journal of Water Process Engineering, 4, 107-133.

[3] Alzahrani, S., Wahab, A., Abdullah, P., \& Jaafar, O. 2018. Journal of Environmental Chemical Engineering Potential tertiary treatment of produced water using highly hydrophilic nanofiltration and reverse osmosis membranes. Biochemical Pharmacology, 1(4), 1341-1349.

[4] Baker, R.W. 2010. Membrane Technology and Application. 2nd ed, John Wiley \& Sons, Ltd., West Sussex.

[5] Chatie le, M., Kayaalp, N., Koyuncu, I., 2017, Desalination of Produced water from Oil Production Fields by Membrane Processes, Desalination, vol. 222, pp. 176-186.

[6] Harrieus, K., Baron, M. \& Fox, R.B. Definions of Terms Relating to Rections of Polymers and to Functional Polymeric Materials. 2002.Kallioinen, M. dan Nystrom, M. 2008. Membrane Surface Characterization, Dalam Li, N.N Fane A.G., Ho W.S.

[7] Kim, I.C.; Yun, H.G.; Lee, K.H. 2001. Preparation of Asymmetric Polyacrylonitrile Membrane with Small Pore Size by Phase Inversion and Post-Treatment Process, Journal of Membrane Science 199 (2002), pp. 75-84.

[8] Kusworo, T.D. 2008. "Fabrication \& characterization of flat sheet \& hollow fiber mixed matrix membrane for gas separation". Thesis. Universitas Teknologi Malaysia.

[9] Kusworo, T.D. 2014. "Enhanced Separation Performance of Cellulose Acetate Membrane For Brackish Water Separation Using Modification of Additives and Thermal Annealing”. Departement of Chemical Engineering, Diponegoro University, Indonesia.

[10] Mulder. 1996 Basic Principles of Membrane Technology, Kluwer Academic Publishers, Netherland.

[11] Mushtaq, A., *, Mukhtar, H.B., \& Shariff, A.M. Effect of Glass Transition Temperature in Enhanced Polymeric Blend Membranes. Procedia Engineering, 2016.06.448, $148: 11$ $-17.2016$

[12] Nadia, Afifah. 2015. Air Terproduksi: Karateristik dan Dampaknya Terhadap Lingkungan. Jurnal Teknik Kimia Institut Teknologi Bandung.

[13] Nunes, S. P. \& Peinemann, K.V. 2001. Membrane Technology in The Chemical Industry, New York: Willey VCH.

[14] Safitri, H.I., Ryanitha, F., dan Aryanti, N. 2012. Teknologi Ultrafiltrasi Untuk Pengolahan Produced water. Jurnal Teknologi Kimia dan Industri. vol.2. no.4. pp.205211. Saunders. K.J. 1994. Organic Polymer Chemistry. Second Edition. London : Black Academic \& Profesional.

[15] Susanto, H., Balakrishnan, M., dan Ulbricht, M., . 2007. Via surface functionalization by photograft copolimerization to low-fouling poliethersulfone-based ultrafiltration membranes, Journal of Membrane Science, vol. 288, pp. 157-167.

[16] Wenten, I.G., 2002, Membrane Technology for Industry and Environmental Protection, UNESCO Centerfor Membrane Science and Technology, Bandung. 